\title{
Dr. Robert (Robin) Harold Stokes
}

\author{
Joseph A. Rard ${ }^{1}$ W. Earle Waghorne ${ }^{2}$
}

Published online: 10 January 2017

(C) Springer Science+Business Media New York 2017

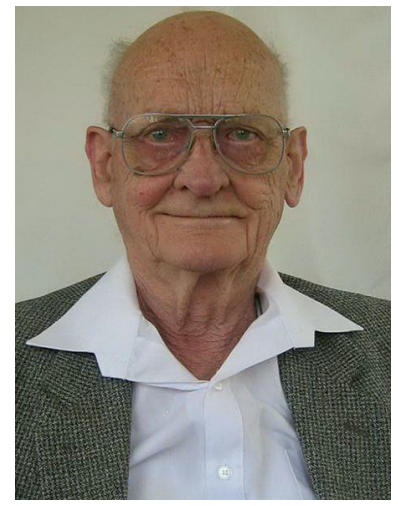

Dr. Robert (Robin) Harold Stokes, 1918-2016

Dr. Robert (Robin) Harold Stokes, a giant presence in the field of solution chemistry, passed away on 15 November 2016 in Armidale, New South Wales, Australia at the age of 97. We doubt that there are any solution chemists who are not familiar with at least some of the achievements of Robin Stokes in our common field of interest. His books "Electrolyte Solutions" [1] (with Robert A. Robinson), "Viscosity of Electrolytes and Related Properties" [2] (with Reginald Mills), and Equilibrium Properties of Aqueous Solutions of Single Strong Electrolytes" [3] (with E. A. Guggenheim) are classical texts describing many experimental methods still in common use. Many of the experimental techniques

Joseph A. Rard

solution_chemistry2@comcast.net

1 Livermore, CA 94550, USA

2 University College Dublin, Dublin, Ireland 
currently used for investigating the physico-chemical properties of liquids were pioneered by him or improved by his research.

Robin Stokes was born in Southsea, England on 24 December 1918, but was raised in New Zealand, and spent the majority of his scientific career in Australia at the University of New England in Armidale, New South Wales.

A summary of the highlights of Robin Stokes' career was published in this journal on the occasion of his 90th birthday [4]. The following year Dr. Ken Marsh conducted a detailed interview with him about his scientific career, and the transcript can be found at: https://www.science.org.au/learning/general-audience/history/interviews-australian-scientists/ professor-robin-stokes-chemist.

Robin Stokes was a Fellow of the Australian Academy of Science (F.A.A.), Fellow of the Royal Society of Chemistry (F.R.S.C.), and Fellow of the Royal Australian Chemical Institute (F.R.A.C.I). He was also a member of the editorial board of this journal until he retired in 2004, not long after his wife Jean Mary (Wilson) Stokes passed away in December 2003.

\section{References}

1. Robinson, R.A., Stokes, R.H.: Electrolyte Solutions, 2nd edn. Butterworths, London (1959); revised edition (1965); reprinted by Courier Dover Publications, New York (2002)

2. Stokes, R.H., Mills, R.: Viscosity of Electrolytes and Related Properties. Pergamon Press, Oxford (1965)

3. Guggenheim, E.A., Stokes, R.H.: Equilibrium Properties of Aqueous Solutions of Single Strong Electrolytes. Pergamon Press, Oxford (1969)

4. Rard, J.A., Palmer, D.A.: Congratulations to Dr. Robin Stokes on his 90th birthday. J. Solution Chem. 37, 1627-1630 (2008) 